\title{
Energy efficiency analysis of the manipulation process by the industrial objects with the use of Bernoulli gripping devices
}

\author{
Volodymyr Savkiv*, Roman Mykhailyshyn*, \\ Frantisek Duchon ${ }^{* *}$, Mykhailo Mikhalishin ${ }^{* * *}$
}

\begin{abstract}
The article deals with the topical issue of reducing energy consumption for transportation of industrial objects. The energy efficiency of the process of objects manipulation with the use of the orientation optimization method while gripping with the help of different methods has been studied. The analysis of the influence of the constituent parts of inertial forces, that affect the object of manipulation, on the necessary force characteristics and energy consumption of Bernoulli gripping device has been proposed. The economic efficiency of the use of the optimal orientation of Bernoulli gripping device while transporting the object of manipulation in comparison to the transportation without re-orientation has been proved.
\end{abstract}

K e y w or d s: Bernoulli gripping device, object of manipulation, manipulator, orientation, industrial robot

\section{Introduction}

At the present stage the issue of energy efficiency while industrial objects transportation and manipulation is of high topicality and urgency. Objects of manipulation are gripped by the device of the industrial robot and are transported from one position into another. In Bernoulli gripping devices [1-6] the lifting force is created on the basis of the aerodynamic effect of attraction appearing due to the use of compressed air. The reliability of functioning of such devices significantly depends on the compressed air expenses to preserve the balance of the object of manipulation as to the gripping device while performing the manipulative functions by the industrial robot. In papers [7-8] the formulae for defining the allowable acceleration of the gripping device while its vertical movement under the conditions of uninterrupted transportation of the objects of manipulation have been derived. That is why the issue of energy efficiency of the process of manipulation with the use of optimal orientation while gripping by means of different methods has arisen. In papers [9-10] the model of optimal orientation of the gripping device while transporting the object of manipulation along the rectilinear trajectory has been suggested as well as the model for defining the optimal orientation of the gripping device while manipulating the objects with off-centered masses as to the axis of the gripping device.

The goal of this paper is to analyze the energy efficiency of the manipulation process of the industrial objects with the use of Bernoulli gripping device and the influence of the gripping method of the objects of manipulation on energy consumption by Bernoulli gripping devices.

\section{Nomenclature}

$H$ : height of the object of manipulation

$E$ : distance from the center of the mass of the object of manipulation to the axis of the gripping device projection OY

$d$ : distance from the center of the gripping device to the friction element of gripping

$R$ : distance from the center of mass of the object of manipulation to the center of the gripping device

$a$ : acceleration of the object of manipulation movement

$\beta$ : $\quad$ the angle between the trajectory and the global plane XOY

$m$ : mass of the object of manipulation

$\varepsilon: \quad$ angular acceleration of the gripping device

$f: \quad$ coefficient of friction

$\omega: \quad$ angular velocity

$Q_{1}, Q_{2}$ : two components of the frontal resistance force

$F_{\text {in }}: \quad$ inertial force

$F_{\text {li }}: \quad$ lifting force

OM: $\quad$ object of manipulation

BGD: Bernoulli gripping device

\section{Methodology}

At given parameters of Bernoulli gripping device (BGD), Fig. 1(a),(b) and the trajectory of its movement, the gen-

* Department of Automation Technological Processes and Production, Faculty of Applied Information Technologies and Electrical Engineering, Ternopil Ivan Pul'uj National Technical University, Ukraine, mykhailyshyn@tntu.edu.ua, ** Department of Robotics and Artificial Intelligence, Faculty of Electrical Engineering and Information Technology, Slovak University of Technology in Bratislava, Slovakia, *** Department of Information Science and Mathematical Modeling, Faculty of Computer Information System and Software Engineering, Ternopil Ivan Pul'uj National Technical University, Ukraine 


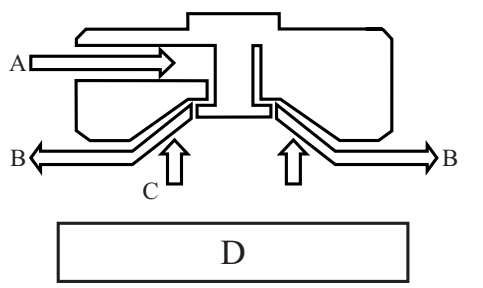

(a)

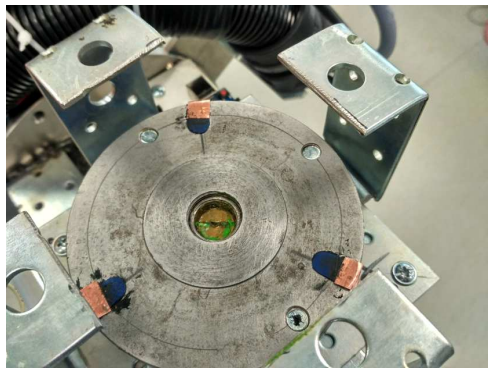

(b)

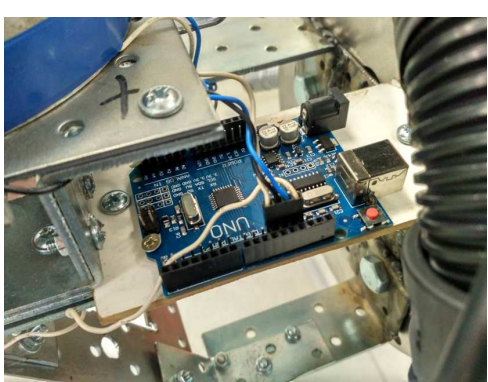

(c)

Fig. 1. Experimental unit: (a) - principle of BGD functioning, (b) - GD fixed at the end effector of the manipulator, (c) - controller of the OM separation from the GD on the basis of Arduino UNO

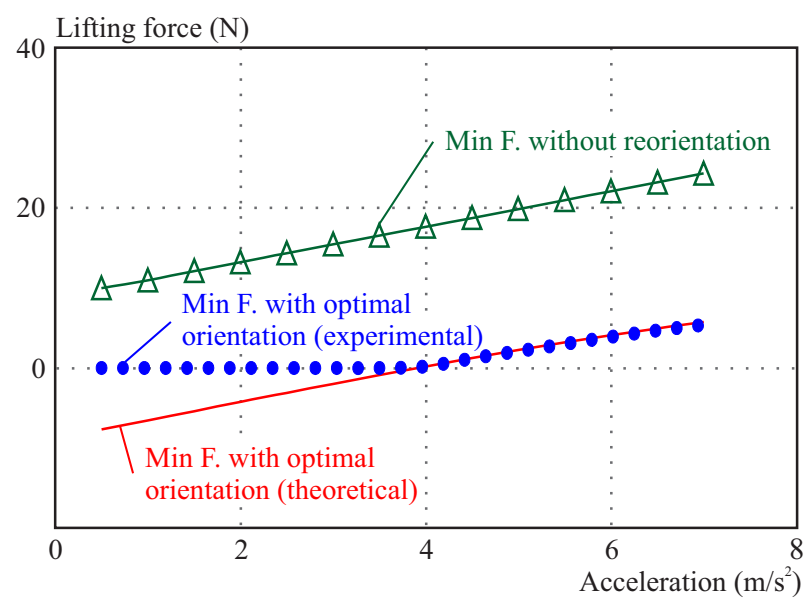

Fig. 2. The diagram of dependence of minimal necessary attractive force on the acceleration of BGD

eral energy consumption while implementing different gripping and unloading methods of the object of manipulation should be defined. The analysis of energy consumption should be conducted for the cases of typical transportation and transportation with the use of BGD re-orientation.

Experimental research, Fig. 1, has been conducted using the movement along the rectilinear trajectory of the object of manipulation $(\mathrm{OM})$. The given trajectory has been implemented during the experimental research with the help of the IRB 4600 manipulator at National Center of Robotics at Slovak University of Technology in Bratislava. Data for the model check has been received with the help of RobotStudio (ABB) software [11]. For the theoretical research of the massive and overall parameters of the $\mathrm{OM}$ for the necessary attractive force, the orientation modeling method has been used, [10].

During the process of the OM transportation without using the orientation optimization model of the GD, its load-lifting capacity should be maximal which corresponds to the most insusceptible variant, and can be estimated with the help of the formula, [10]

$$
\begin{aligned}
F_{\mathrm{np}} & =m\left[g\left(\frac{\sin \alpha}{f}-\cos \alpha\right)-\omega^{2}\left(\frac{E}{f}-\frac{H}{2}\right)+\right. \\
& \left.+\varepsilon\left(\frac{H}{2 f}+E\right)\right]-\left(Q_{1}+Q_{2}+F_{\text {in }}\right) \times \\
& \times\left(\frac{\cos (\alpha+\beta)}{f}+\sin (\alpha+\beta)\right)
\end{aligned}
$$

where $\alpha$ is the angle between the global axis $\mathrm{OZ}$ and the axis of the gripping device.

Reduction of energy consumption while using the model for the optimal orientation of BGD is connected with the reduction of the necessary minimal attractive force needed to hold the OM, Fig. 2, that is by reducing consumption of the compressed air. Optimal orientation $(\alpha)$ is defined by the following transcendental equation, [10]

$$
\begin{aligned}
& m\left[\varepsilon\left(R^{2}+\frac{H d}{2 f}\right)-\frac{d}{f} \omega^{2} E\right]+ \\
& +m\left\{\begin{array}{c}
\frac{d}{f}(g \sin \alpha-a \cos (\alpha+\beta))- \\
-g\left(E \cos \alpha-\frac{H}{2} \sin \alpha\right)- \\
-a\left(E \sin (\alpha+\beta)+\frac{H}{2} \cos (\alpha+\beta)\right)
\end{array}\right\} \\
& -Q_{1}\left[\left(\frac{d}{f}+\frac{A}{2}\right) \cos (\alpha+\beta)+\left(E-\frac{A}{2}\right) \sin (\alpha+\beta)\right]+ \\
& +Q_{2}\left[\left(\frac{d}{f}+H\right) \cos (\alpha+\beta)+E \sin (\alpha+\beta)\right]=0
\end{aligned}
$$

The optimal orientation is calculated for each Section of the trajectory, but the minimum required lifting force on Sections 3-6 of the trajectory is determined from (1) at an angle $\alpha$ (optimal for the acceleration Section 3), at the point T2 when the optimal orientation is stored for acceleration, and the 

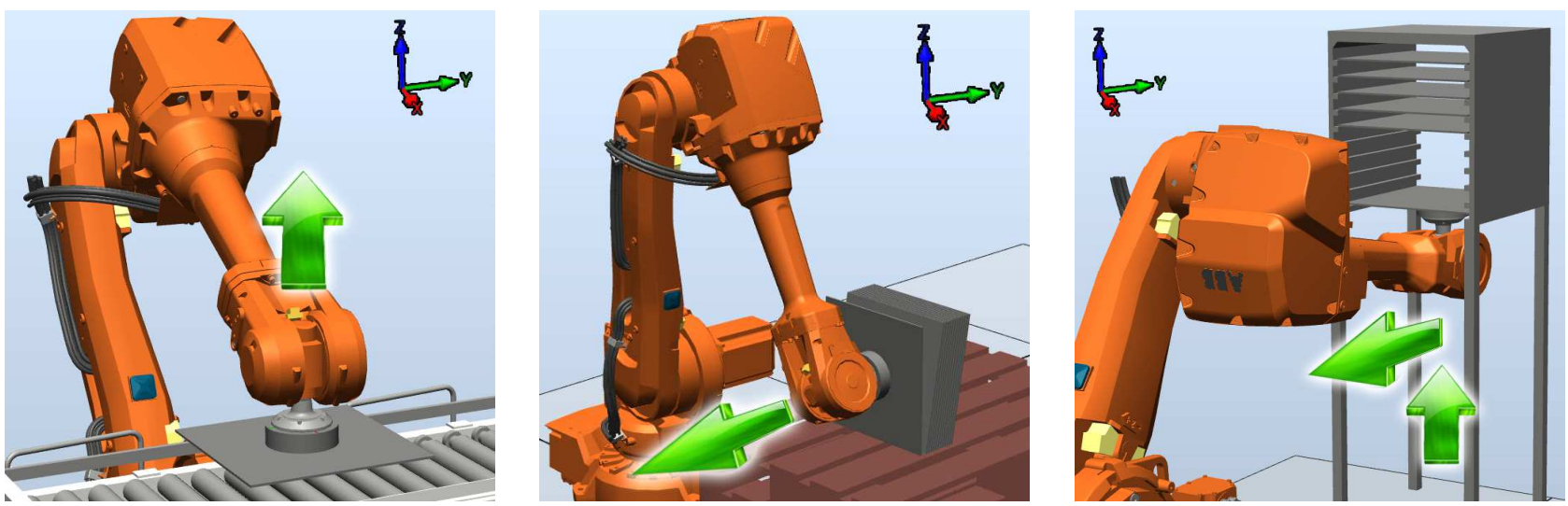

Fig. 3. The schemes of gripping of the object of manipulation:(a) - from the horizontal position, (b) - from the vertical position, (c) from the storage device

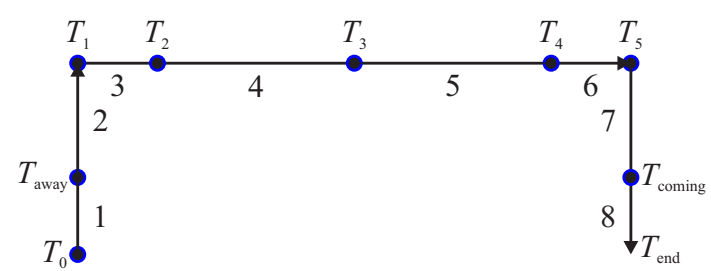

Fig. 4. The trajectory of the object of manipulation transportation with the help of Bernoulli gripping device

acceleration is no longer present on Section 4 path beginning with a uniform speed. Experimental data on the minimum required force of lifting $F_{1 \mathrm{i}}$ are obtained from the condition of inseparable of the object manipulation from the gripping device (with constant acceleration and optimal orientation). By measuring the force of lifting at positive values of the sensor, Fig. 1(c).

The calculations of the optimal orientation, force characteristics of BGD and energy consumption for the OM transportation, have been conducted under the following parameters: $a=5 \mathrm{~m} / \mathrm{s}^{2}, m=0.9 \mathrm{~kg}, f=0.404, H=5 \mathrm{~mm}, \beta=0$, $\omega=0, \varepsilon=0$

For the interval of the acceleration from 0 to 4 , one can notice the tendency of the attractive force towards the needlessness of retention of the object of manipulation on the gripping device. The value of the interval for which this tendency will preserve significantly depends on the coefficient of the object of manipulation friction to the friction elements of the gripping device.

General energy consumption for performing the transportation operation includes work carried out by the manipulator and BGD. To calculate the work performed by Bernoulli gripping device the formula presented below is used

$$
A=N_{c} t=P_{r} Q t
$$

where are: $P$ - rail pressure, $Q$ - compressed air consumption through the slot of GD, $N_{c}$ - consumption capacity of BGD. Further calculations of energy consumption by BGD will be conducted on the basis of technical characteristics of the NCT-100 gripping device (by Bosch), [1].

Work spent by the manipulator to perform the transportation operation is convenient to be calculated with the help of the functional possibilities of the software package RobotStudio (ABB) [12].

\section{Results and Discussion}

First and foremost, the typical gripping methods of the object of manipulation of plate type which are the most often used in practice:

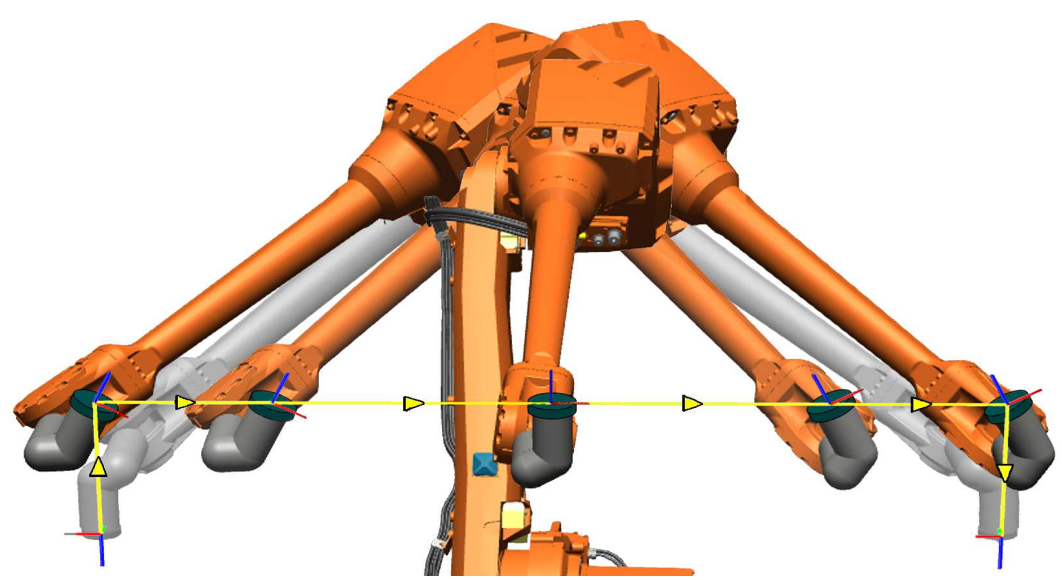

Fig. 5. Modeling of the orientation optimization method of Bernoulli gripping device in RobotStudio software environment 

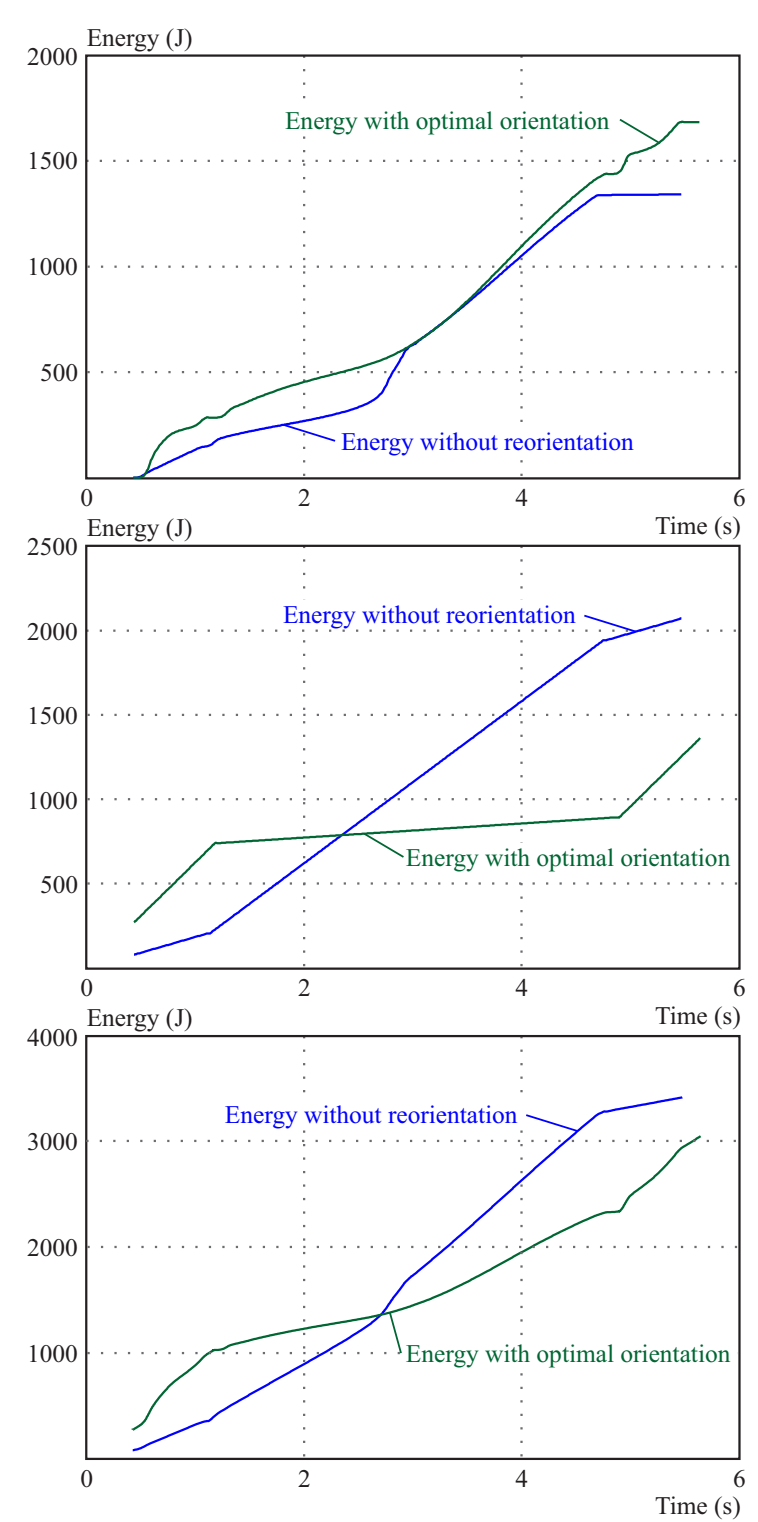

Fig. 6. Graphs showing the energy consumption for the object of manipulation transportation using the first method of gripping

- Gripping of the object of manipulation which lies on the horizontal plane parallel to the global plane XOY. The bend of the object of manipulation is conducted by the movement of the gripping device into the direction $(\mathrm{OZ})$, which is perpendicular to the horizontal plane, Fig. 3(a).

- Gripping of the object of manipulation, beyond the vertical plane, perpendicular to the global plane XOY. The bend of the object of manipulation is conducted by the movement of the gripping device into the direction parallel to the horizontal plane, Fig. 3(b)

- Gripping of the object of manipulation, located in the storage device, parallel to the global plane XOY. The bend of the object of manipulation is conducted by the movement of the gripping device into the direction $(\mathrm{OZ})$, perpendicular to the horizontal plane, and then parallel to the horizontal plane, Fig. 3(c).

Let us study the first method of transportation of the object of manipulation with gripping the object of manipulation which lies on the horizontal plane parallel to the global plane XOY. The bend of the object of manipulation is conducted
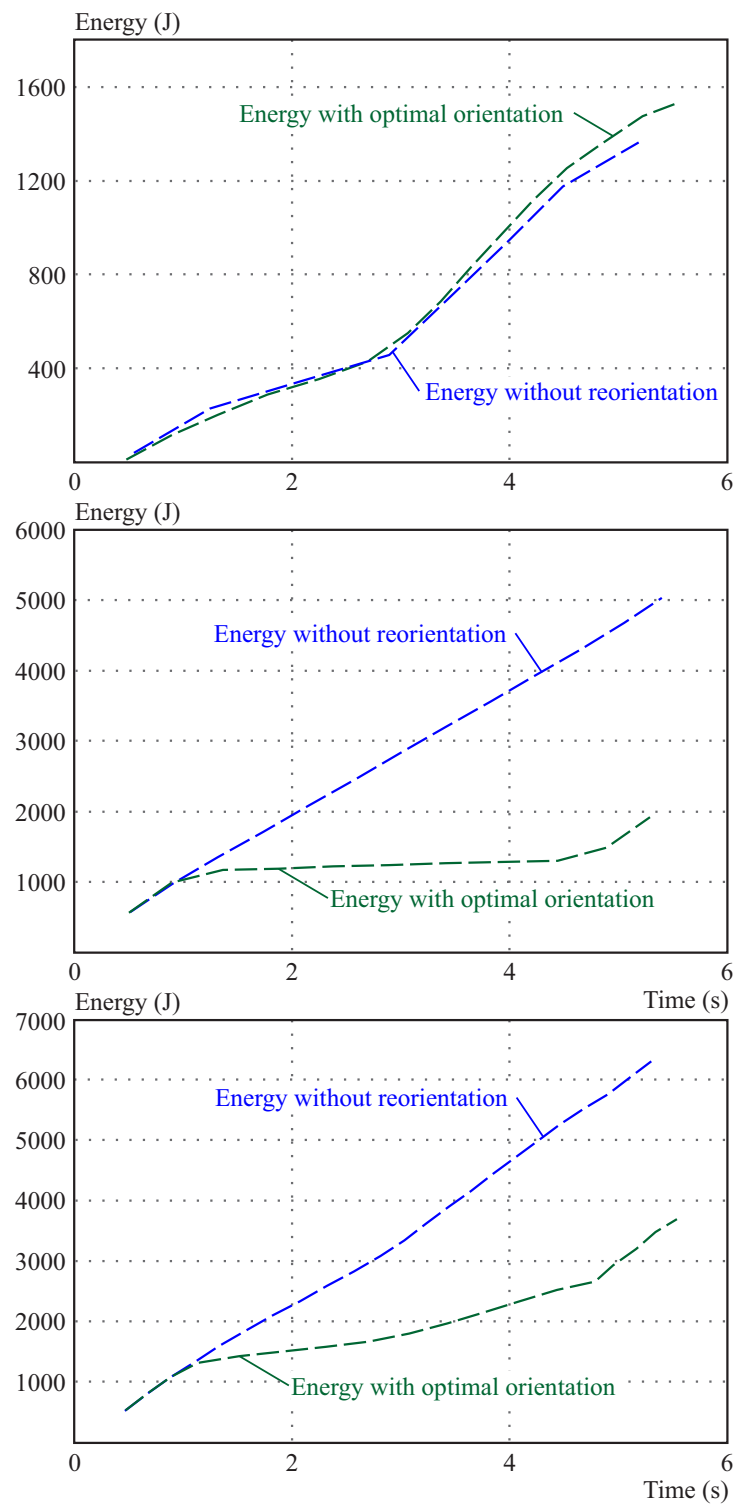

Fig. 7. Graphs of energy consumption for transportation of the OM using the second method of gripping

by the movement of the gripping device in the direction $(\mathrm{OZ})$, perpendicular to the horizontal plane XOY, Fig. 3(). We will use the trajectory which has the form introduced in Fig. 4.

While transportation of the object of manipulation without re-orientation in all sections of the trajectory the horizontal orientation will be preserved. While transportation of the object of manipulation with optimization of BGD orientation this methodology will be used, Fig. 5, [10]

In Section 1 of the trajectory, the orientation of the gripping device will not change. In Section 2 of the trajectory, the orientation of the gripping device will change from horizontal into optimal one which corresponds to the parameters of the movement in Section 3 (equal accelerated movement of the GD). In Section 3 of the trajectory, the optimal orientation of the gripping device will be preserved, while in Section 4 the orientation of the gripping device will change from the previous orientation into the optimal orientation which corresponds to the parameters of the movements in Sections 4-5 (uniform motion of the gripping device). Farther in Section 5 the re-orientation of the gripping device will take place from 

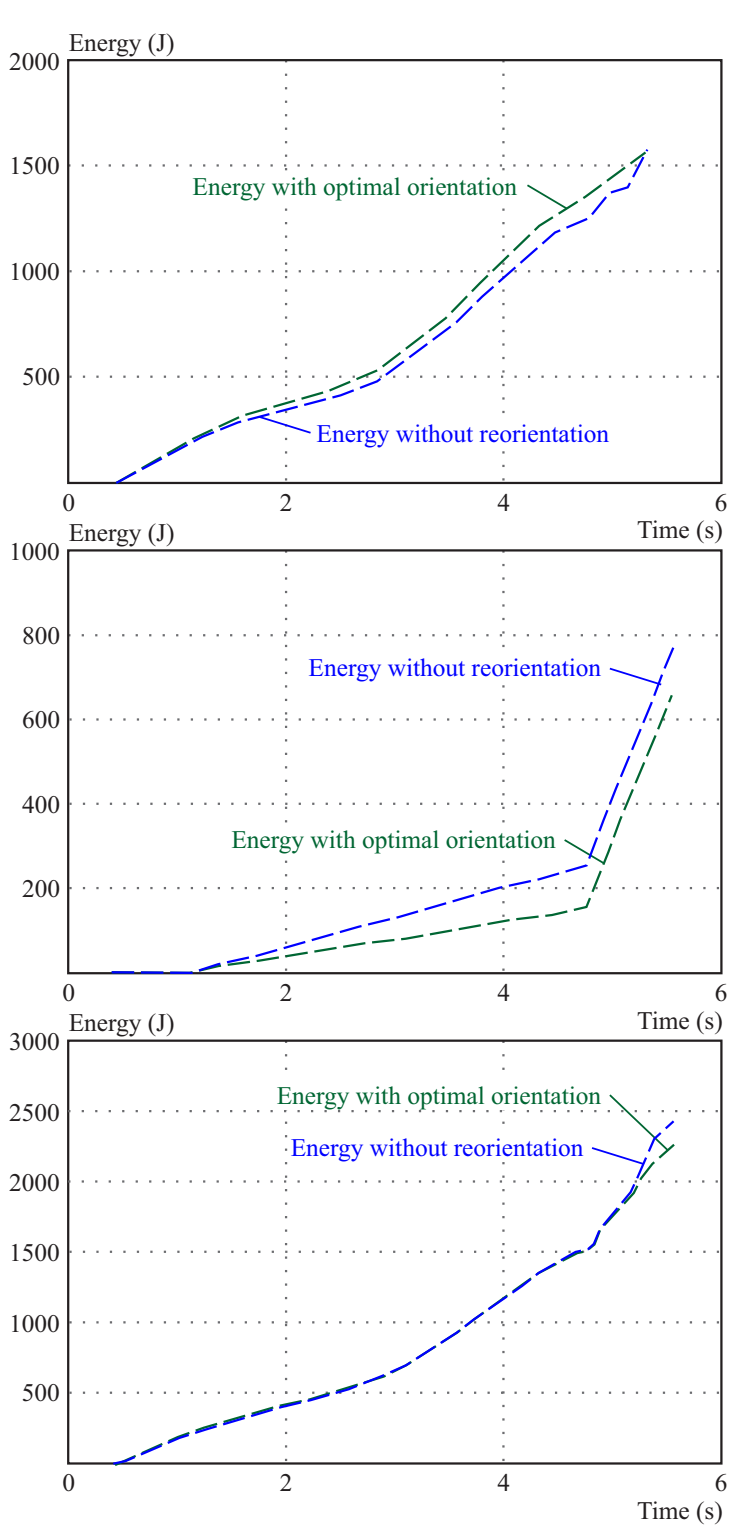

Fig. 8. Graphs of the energy consumption for the OM transportation using the third method of gripping

the previous one into the orientation which will be optimal for Section 6 (deceleration of the gripping device). In Section 6 the optimal orientation will be preserved all along. Next to Section 6, in Section 7, re-orientation of the gripping device from the previous orientation into the horizontal one takes place to unload the object of manipulation.

In Section 8 of the trajectory during the invariable orientation, the unloading of the object of manipulation takes place. According to the characteristics of Bernoulli gripping device NCT-100 the calculations of the energy consumption for keeping the object of manipulation at working out the given trajectory by the robot and time parameters has been conducted, Fig. 6.

As Fig. 6 shows, minimizing the energy consumption of the gripping device on the account of the optimal orientation, we have received the increased energy consumption to perform the orientational movements by the manipulator as well as the energy consumption for the re-orientation from the beginning until the end of the trajectory has partially increased. The same way as during the orientation from the horizontal position of the gripping device into the optimal one, it will take place through the orientation at which the maximal lifting power should be necessarily provided. In general, the overall workload spent for transportation while using the orientation optimization method has been reduced by $11 \%$.

Let us examine the second method of gripping of the object of manipulation, located in the storage device, parallel to the global plane XOY. The bend of the OM takes place by the movement of the gripping device into the direction $(\mathrm{OZ})$, perpendicular to the horizontal plane and then parallel to the global plane, Fig. 3(c). We will use the same trajectory as in the previous casem, Fig. 4. While transporting the object of manipulation without re-orientation in all sections of the trajectory, the vertical orientation will be preserved, except Section 7. In Section 7 re-orientation of the OM will take place from the vertical into the horizontal position, and in Section 8 its unloading onto the horizontal plane.

During the transportation of the OM using the method of orientation optimization of Bernoulli gripping device, Fig. 7, in Section 1 of the trajectory, orientation of the gripping device will not change. In Section 2 of the trajectory, the orientation of the gripping device will change from vertical, which has been at the beginning of gripping, into the optimal orientation which will be in Section 3 during the acceleration. Further actions will take part in correspondence with the gripping method that has been examined above.

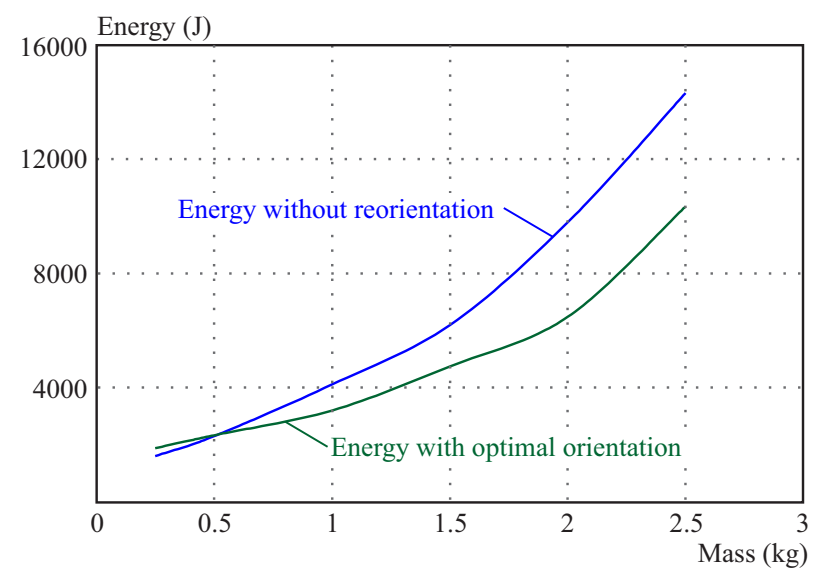

Fig. 9. Graphs representing dependence of the total work spent on the mass of the OM while using the first gripping method

According to Fig. 7, minimizing the energy consumption of gripping device on account of the optimal orientation, we have got the increase in energy consumption to carry out orientating movements by the manipulator by $5 \%$. Summarizing general amount of work spent for transportation using the method of optimal orientation of BGD, energy consumption has decreased by $43 \%$.

Let us study the third method of gripping of the object of manipulation, which is located in the storage device, parallel to the global plane XOY. The bend of the object of manipulation takes place by movement of the gripping device into the direction $(\mathrm{OZ})$, perpendicular to the horizontal plane, and then parallel to the global plane, Fig. 2(c). We will use the same trajectory as in the previous case, Fig. 3. While transporting the object of manipulation without re-orientation in 


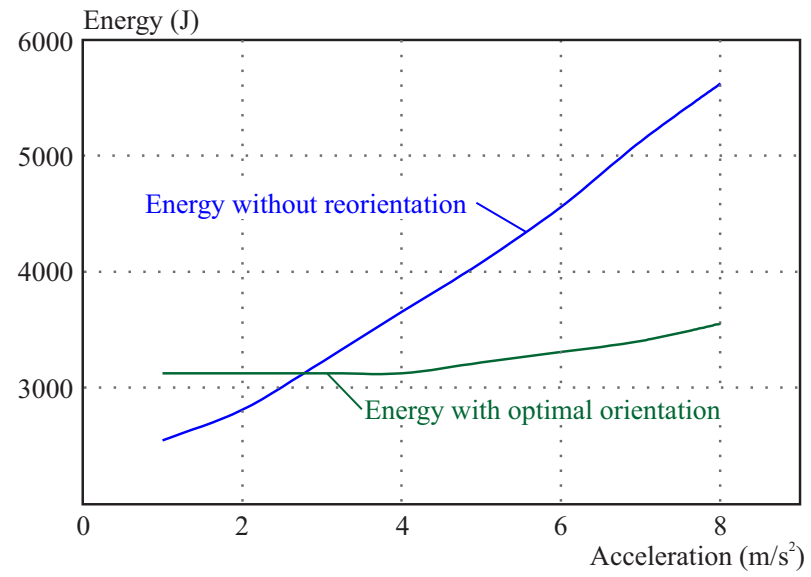

Fig. 10. Graphs of the total work spent for the transportation of the om with different acceleration using the first method of gripping

all sections of the trajectory, the horizontal orientation will be preserved, except Section 7, where re-orientation of the OM for 180 degrees will take place. In Section 8 unloading of the object of manipulation into the horizontal plane will occur.

During the transportation of the OM using the method of orientation optimization of Bernoulli gripping device, Fig. 8, in Section 1 of the trajectory, the initial orientation will be preserved. In Section 2 the orientation of the gripping device will be changing from the horizontal. Into the optimal one which will be in Section 3 at the moment of acceleration. Further actions will take part in correspondence with the gripping method that has been examined above.

As Fig. 8 shows, minimizing the energy consumption of the gripping device on the account of the optimal orientation, we have received the increase in energy consumption to carry out orientating movements by the manipulator by $5 \%$. Summarizing general amount of work spent for transportation using the method of optimal orientation of BGD, energy consumption has decreased by $7 \%$.

The analysis of the work spent for transportation of the OM along the typical trajectory, Fig. 3, with the unchanging movement parameters and parameters of the object of manipulation for different gripping method shows that the most optimal method of gripping (from the viewpoint of energy consumption) will be gripping of the OM by the lower horizontal plane.

The influence of the mass of the object of manipulation should be evaluated as one of the most important factors affecting force characteristics of Bernoulli gripping device and at the same time the increase in energy consumption, Fig. 9.

Figure 9 shows that the efficiency of implementation of the orientation optimization method has been increasing in correspondence with the increase of the mass of the object of manipulation. When the mass equals $1 \mathrm{~kg}$ the energy consumption for transportation of the OM decreased by $20 \%$, while when the mass is $2 \mathrm{~kg}$ it decreased by $32 \%$. At the same time, the use of this method is not reasonable for given parameters and technical characteristics of the robot IRB 4600 when $m<0.6 \mathrm{~kg}$.

Besides the mass of the object of manipulation, transportation is under the significant influence of the acceleration in all the sections of the trajectory. That is why it is important to study the influence of the acceleration, as the main constituent part of the inertial force, which occurs at the moment

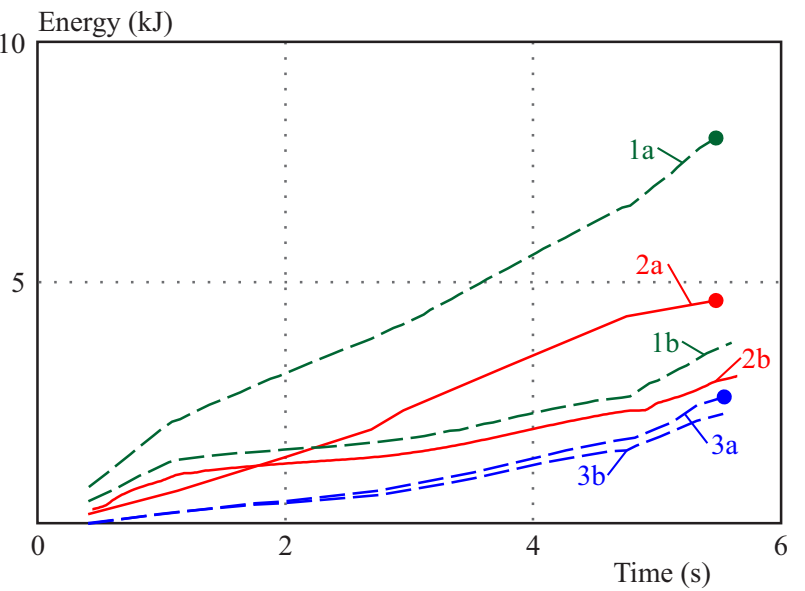

Fig. 11. Graphs showing the total energy consumption for the transportation of the OM with different capture methods

of movement of the object of manipulation, on the force characteristics and energy consumption of BGD at the moment of transportation of the OM, Fig. 10

According to Fig. 10, the efficiency of the implementation of the orientation optimization method is being increased with the increase of the acceleration of the object of manipulation. For the $\mathrm{OM}$ of $1 \mathrm{~kg}$ when the acceleration of the OM equals $=3 \mathrm{~m} / \mathrm{s}^{2}$ the energy consumption has decreased by $5 \%$, while under the acceleration of $a=8 \mathrm{~m} / \mathrm{s}^{2}$ by $46 \%$. At the same time, for given movement parameters and technical characteristics of the robot IRB 4600 the use of this method is not reasonable when $a<3 \mathrm{~m} / \mathrm{s}^{2}$. Though, while programming industrial robots, restrictions as to the acceleration are not usually used.

Such transportation leads to the increase of energy consumptions. Thus for the typical trajectory, Fig. 4, not having given the restriction for acceleration of the final chain of the manipulator in Sections 1,2,7,8 of the trajectory, the software package RobotStudio automatically restricts it to $a=10 \mathrm{~m} / \mathrm{s}^{2}$, and in Sections $3,4,5,6$ to $a=7 \mathrm{~m} / \mathrm{s}^{2}$. Let us calculate the energy consumption for such data under the optimal orientation of BGP, having restricted the acceleration till $5 \mathrm{~m} / \mathrm{s}^{2}$, taking the equal time of the transportation, Fig. 11.

As Fig. 11 presents, the energy consumption to transport the OM when the acceleration is not restricted increases. In such cases, the method of orientation optimization of Bernoulli gripping device will have a greater effect. Thus, for the OM gripping by the upper horizontal plane, the energy consumption for the transportation will decrease by $35 \%$, for the OM gripping from the vertical plane by $54 \%$, and for the OM gripping by the lower horizontal plane by $14 \%$.

\section{Conclusions}

In the paper, the energy efficiency of the objects of manipulation using the orientation optimization method has been analyzed as well as its comparison with the method without re-orientation of the gripping device. The analysis of the work expended for the transportation of the object of manipulation for different gripping methods showed that the most effective method of gripping (from the viewpoint of energy consumption) is its gripping by the lower horizontal plane. The use of the orientation optimization method of the gripping 
device in the process of the object manipulation allowed decreasing energy consumption to $54 \%$ in comparison with the transportation without re-orientation. It has been proved that while increasing the mass of the object of manipulation and acceleration of the gripping device, the energy efficiency of the orientation optimization method increases in comparison to the object transportation without re-orientation.

\section{REFERENCES}

[1] Official website of Bosch Rexroth [Electronic source] - Retrieved: http://www.boschrexroth.com/pneumatics-catalog.

[2] Official website of Festo AG \& Co [Electronic source] - Retrieved: https://www.festo.com/net/sv ${ }_{s} \mathrm{e} /$ SupportPortal/default.aspx?cat $=4564$.

[3] Official website of Schmalz [Electronic source] - Retrieved: https://www.schmalz.com/en/vacuum-technology-for-automation/vacuum-components/special-grippers/floating-suction-cups /floating-suction-cups-sbs.

[4] X. Li and T. KAGAWA, "Development of a new noncontact gripper using swirl vanes", Robotics and Computer-Integrated Manufacturing, vol. 29, no.1, pp. 63-70, 2013.

[5] X. Li and T. KAGAWA, "Theoretical and experimental study of factors affecting the suction force of a Bernoulli gripper", Journal of Engineering Mechanics, vol. 140, no.9., ISBN 04014066, 2014.

[6] V. Savkiv, O. Fendio and H. Savkiv, "Improvement of the construction of Bernoulli gripping devices of the automatical loading devices", Scientific journalof the Ternopil national technical university, vol. 15 , no.3, pp. 64-74, 2010, (Ukraine: Udoskonalennya konstruktsiyi strumenevykh ezhektsiynykh zakhoplyuvachiv avtomatychnykh prystroyiv zavantazhennya).

[7] G. MANTRIOTA, "Theoretical model of the grasp with vacuum gripper", Mechanism and machine theory, vol. 42, no.1, pp. 2-17, 2007.

[8] G. MANTRIOTA, "Optimal grasp of vacuum grippers with multiple suction cups", Mechanism and machine theory, vol. 42, no.1, pp. 18-33, 2007.

[9] R. Mykhailyshyn, Y. Prots and V. Savkiv, "Optimization of bernoulli gripping device's orientation under the process of manipulations along direct trajectory", Scientific Journal of the Ternopil National Technical University, vol. 81, no.1, pp. 107-117, 2016.

[10] V. Savkiv, R. Mykhailyshyn, O. Fendo and M. Mykhailyshyn, "Orientation Modeling of Bernoulli Gripper Device with OffCentered Masses of the Manipulating Object", Procedia Engineering, vol. 187, pp. 264-271, 2017.
[11] Official website of $A B B$ [Electronic source] - Retrieved: http:/ /new.abb.com/products/robotics/robotstudio.

Received 30 May 2017

Volodymyr Savkiv (Assoc Prof, PhD) was born in Avhustivka, Ukraine, in 1973. He received the MSc degree in Automation and $\mathrm{PhD}$ at Ternopil Ivan Pul'uj National Technical University 1995 and Sebastopol National Technical University 1999 respectively. Now, he is a staff member of the Department of automation technological processes and production, Faculty of Applied Information Technologies and Electrical Engineering, Ternopil Ivan Puluj National Technical University. His research is oriented on development of Bernoulli gripping devices and robotics.

Roman Mykhailyshyn (PhD student) born in Ternopil, Ukraine, in 1992, received MSc degree at Ternopil Ivan Pul'uj National Technical University in 2014. Now, he is a staff member of the Department of automation technological processes and production, Faculty of Applied Information Technologies and Electrical Engineering, Ternopil Ivan Pul'uj National Technical University. His research is oriented on simulation orientation Bernoulli gripping devices, development of Bernoulli gripping devices and robotics.

František Duchoň (Assoc Prof, Ing, PhD) was born in Krnov, Czech Republic, in 1981. He received the MSc degree in Automation and $\mathrm{PhD}$ in Automation and Control from the Slovak University of Technology, Bratislava, in 2005 and 2010 respectively. From 2006 to 2008. He was a PhD student. From 2008 to 2011, and an Intern Researcher with the Department of Robotics and Artificial Intelligence, Faculty of Electrical Engineering and Information Technology, Slovak University of Technology in Bratislava. Since 2011, he is an Associate Professor at the same place of work. His research interests include mobile robotics and robotic manipulators.

Mykhailo Mikhalishin (Assoc Prof, $\mathrm{PhD}$ ) was born in Cebriv, Ukraine, in 1946. He received the MSc degree and PhD in Ternopil Ivan Pul'uj National Technical University 1968 and University of Tartu 1975 respectively. Now, he is the head of the Department of Information Science and Mathematical Modelling, Faculty of Computer Information System and Software Engineering, Ternopil Ivan Pul'uj National Technical University. His research is oriented on mechanics of the solid deformable body. 